be followed in the sea. It is practicable to "rack" the rivers, permitting the ascent of the fish only through a narrow gap. It is even possible to count the fish that so pass during short sample times that can be averaged. Then the ratio of fish ascending to spawn to the run of fish four or five years later (when the hatched fry return from the sea) can be calculated. Comparisons over a number of years can so be made and a maximum degree of exploitation permitted. The method is, of course, much more complex than is here indicated, but it is all highly practicable. To such statistical investigation would, of course, be added a prolonged study of the spawningbeds in the head-waters, even the artificial improvement and control of the spawning and the elimination of the natural enemies of the very young fry. To some extent such investigations have been carried out -in spite, it is said, of the opposition of the Secretary of Commerce, whose non-appreciation of the value of scientific investigation was all that might have been expected.

Now, however, the commercial interests are threatened and the administrative attitude is likely to change-with results of value not only to the industry, but also to general biology.

\section{J. J.}

\section{Recent Applications of Interference Methods. ${ }^{1}$}

PROF. MICHELSON said that since the armistice he had been interested in three questions: the measurement of the earth tides, a re-determination of the velocity of light, and the measurement of the diameters of fixed stars.

In the first of these problems the experiment reduced itself to the measurement of the difference in the movements of the free surfaces of water at the extremities of a long pipe submerged in the ground. Preliminary work was carried out with microscopes, but the final records were obtained from the movements of interference fringes. Records were taken at intervals of two hours on a kinematograph which worked continuously for a year. The results obtained were plotted, and found to agree very closely with those calculated from theory.

In the re-determination of the velocity of light the arrangement ultimately to be employed was the same as that previously used by Prof. Michelson, except that a much longer distance-say, twenty-five mileswas contemplated. This was to permit a larger angular movement of the rotating mirror, which in this case consisted of an octagon of glass rotating at about 1000 revolutions per second. If the speed were so adjusted that the octagon described $45^{\circ}$. during the time taken by light to pass to the distant mirror and back, the returning beam would be undeviated. This condition could be determined to a much higher degree of precision than was possible for the angular measurements involved in previous determinations. The application of interference to this work lay in the method of making the angles of the octagon very accurately equal.

The third problem, that of measuring the diameters of the stars, was solved on lines which Prof. Michelson had applied many years ago to the measurement of the separation of double stars. The method consists in varying the separation of two slits in front of the object-glass of a large telescope until the visibility of the parallel diffraction fringes seen in the focal plane of the telescope is a minimum. No exist-

I Abstract of the Sixth Guthrie Lecture, delivered before the Physical Soriety of Lonton on March $x \mathrm{r}$ by Prof. A. A. Miche'son, of the University of Chicago.

NO. 2685 , VOL. IO77 ing telescope is of large enough aperture for this condition to be reached in the case of single stars; but by attaching an arrangement of mirrors in front of the large Ioo-in. telescope at Mount Wilson Observatory, which in effect increased its aperture to $20 \mathrm{ft}$., it had been possible to obtain a result for the star $\alpha$ Orionis, the fringes from which disappeared when the slits were separated by about ro $\mathrm{ft}$. This corresponded to an angular diameter of just under a twentieth of a second.

\section{University and Educational Intelligence.}

Prof. G. Elliot Smith is delivering two lectures, one at Groningen University on April it and the other at the University of Utrecht on April 16, entitled "Vision and Evolution." These lectures are being given under the auspices of the Dutch Royal Academy of Sciences, and form part of the scheme for the exchange of lecturers between this country and Holland which has been referred to recently in these columns.

The Summer School of Civics, organised by the Civic Education League, is to be held this year at Guildford (Surrey) on July 30-August I4. Courses on economics, anthropology, social biology, maternity and child welfare, sociology, civics, and social psycho logy will be among those offered; while practical training in the presentation of civics (through public speaking, etc.) and in the regional approach to civics will also be provided. Full particulars may be had from the secretary, Miss Margaret Tatton, Leplay House, $6_{5}$ Belgrave Road, Westminster, S.W.I.

THE governing body of Emmanuel College, Cambridge, is offering a research studentship of the annual value of ${ }_{5} 5 \mathrm{ol}$., which will be tenable for two vears and renewable in exceptional circumstances for a third year. The studentship is offered to a research student commencing residence at the college in October next, and applications should reach the Master of Emmanuel not later than September $x 7$. The award, which will be made on the evidence submitted by the candidates, should include two certificates of good character, an account of their career with the names of professors or teachers under whom they have studied, a statement of the proposed line of research, and evidence of ability to undertake that particular class of work.

When the closing of the Finsbury Technical College was announced by the City and Guilds Institute in July last the many friends of the college began to take steps to avert the threatened disaster. A defence committee, consisting principally of old students, was formed, and it presented a petition to the governing body signed by many workers in all branches of science and by others connected with industry and with some of the City Companies who felt that all possible steps should be taken to continue the college. The professional institutes and learned societies presented a memorial signed by their presidents, and other bodies, including the National Union of Scientific Workers, took such other action as seemed likely to help. The strong hope that, with the assistance of the London County Council and the Board of Education, the future of the college might be assured for the next five years was recently expressed by the governing body to the defence committee and the institutions concerned. The success of the negotiations is now announced, and it may be hoped that the permanence of the college will in the meantime be assured without its distinctive character being in any way impaired. 